\title{
Anti-cancer properties of quercetin in osteosarcoma
}

\author{
Parisa Maleki Dana ${ }^{1}$, Fatemeh Sadoughi ${ }^{1}$, Zatollah Asemi ${ }^{1 *}$ (i] and Bahman Yousefi ${ }^{2,3^{*}}$
}

\begin{abstract}
Osteosarcoma is a primary bone tumor. Although it is a rare disease in general, it is the most common primary bone tumor among children. Despite the significant advances made in the field of osteosarcoma treatment, the outcomes of this disease are still unfavorable. Besides, there is still no targeted therapy for osteosarcoma that can be used in clinical settings. Quercetin is a member of the phytochemical family which is used for different diseases including cardiovascular diseases, diabetes, and cancer. Its anti-cancer effects are examined in many types of cancer including breast, colon, lung, prostate, and pancreatic cancers and have shown promising results. Herein, the studies dealing with the antitumor roles of quercetin in osteosarcoma are reviewed in this article. We take a look into quercetin's ability to affect proliferation, apoptosis, invasion, and chemo-resistance of the osteosarcoma cells through regulating protein expression and signaling pathways.
\end{abstract}

Keywords: Quercetin, Osteosarcoma, Apoptosis, Proliferation, Cell viability

\section{Background}

Osteosarcoma is a high-grade primary bone tumor that is defined by spindle cells originated from mesenchyme. Overall, osteosarcoma is a rare disease. However, it is the most common primary bone malignancy among children [1]. While this disease occurs sporadically, approximately $70 \%$ of tumor specimens show an abnormality in the chromosome. Moreover, regulation of cell cycle has been reported to demonstrate inherited defects in some cases [2]. In patients younger than 25 years old or older than 59 years, the age-adjusted incidence of osteosarcoma is 4 per 1 million people. However, this number drops to fewer than 2 per 1 million in people ages 25 to 59 years. The incidence of osteosarcoma is bimodal. The first peak occurs at the ages of puberty, implying the ages

\footnotetext{
*Correspondence: Asemi_r@yahoo.com; bahmanusefi@gmail.com 1 Research Center for Biochemistry and Nutrition in Metabolic Diseases, Institute for Basic Sciences, Kashan University of Medical Sciences, Kashan, I.R. of Iran

${ }^{2}$ Stem Cell Research Center, Tabriz University of Medical Sciences, Tabriz, Iran

Full list of author information is available at the end of the article
}

of 15 to 19 in boys and the ages of 10 to 14 in girls. The second peak occurs in the elderly with the age of 75 years [3]. Noteworthy, osteosarcoma is rare before the age of 5 [4]. With the application of multimodal chemotherapy, disease-free survival of patients with high-grade osteosarcoma has been improved to more than $60 \%$ compared to $10-20 \%$ which was reachable with the surgery as the only therapeutic approach. Currently, treatment of osteosarcoma is a combination of surgery and chemotherapy both before and after the surgery. Cisplatin, methotrexate, doxorubicin, and ifosfamide are common cytotoxic agents used for chemotherapy [5]. Although several chemotherapy regimens have been applied in the past 20 years, survival rates of patients are still not satisfying and no practical targeted therapy is discovered [6]. Therefore, it is important to investigate different therapeutic methods and anti-tumor agents in order to find an approach that provides a higher survival rate.

Quercetin is a common member of phytochemicals which can be found in daily foods, such as vegetables, nuts, and teas $[7,8]$. Quercetin is a commercially accessible supplementary agent. It is reported that oral administration of $1 \mathrm{~g}$ quercetin per day is safe and is absorbed

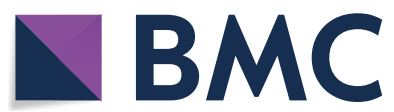

(c) The Author(s) 2021. This article is licensed under a Creative Commons Attribution 4.0 International License, which permits use, sharing, adaptation, distribution and reproduction in any medium or format, as long as you give appropriate credit to the original author(s) and the source, provide a link to the Creative Commons licence, and indicate if changes were made. The images or other third party material in this article are included in the article's Creative Commons licence, unless indicated otherwise in a credit line to the material. If material is not included in the article's Creative Commons licence and your intended use is not permitted by statutory regulation or exceeds the permitted use, you will need to obtain permission directly from the copyright holder. To view a copy of this licence, visit http://creativeco mmons.org/licenses/by/4.0/. The Creative Commons Public Domain Dedication waiver (http://creativecommons.org/publicdomain/ zero/1.0/) applies to the data made available in this article, unless otherwise stated in a credit line to the data. 
up to $60 \%$ [9]. Several studies have shown that quercetin plays a variety of pharmacological roles, including anti-proliferation, anti-oxidant, anti-inflammation, antimicrobial and anti-diabetes activities [8, 10-12]. Furthermore, quercetin is indicated to exert various anti-tumor effects both in vitro and in vivo against several cancers, such as ovarian cancer, colorectal cancer, lymphoma, gastric cancer, and breast cancer [13-17]. Herein, the studies dealing with the role of quercetin in the treatment of osteosarcoma are reviewed.

\section{Osteosarcoma pathogenesis}

The molecular pathogeneses of osteosarcoma are heterogeneous (Fig. 1) [18]. Predisposition to osteosarcoma has been related to some syndromes, such as Li-Fraumeni syndrome, Retinoblastoma, Bloom's syndrome, Werner's syndrome, and Rothmund-Thomson syndrome [19-25]. The most common syndrome that predisposes to pediatric sarcomas is Li-Fraumeni syndrome in which the TP53 gene is mutated in the germline. TP53 encodes p53 which is a transcription factor regulating DNA repair genes and inducing post-damage apoptosis [26]. It is estimated that $30 \%$ of patients with Li-Fraumeni syndrome develop osteosarcoma. Furthermore, $18-26.5 \%$ of patients with sporadic osteosarcoma have shown somatic p53 loss
[27, 28]. Retinoblastoma also leads to a predisposition to osteosarcoma. RB1 gene encodes retinoblastoma protein $\mathrm{pRb}$ which binds to the transcription factors of E2F family [29]. pRb loss occurs frequently in osteosarcoma sporadic cases and is associated with poor outcomes [30, 31]. Mutations in genes of RecQ helicases are also related to some rare autosomal recessive disorders, such as Rothmund-Thomson syndrome, Bloom's syndrome, and Werner's syndrome. These disorders are reported to be correlated to the higher osteosarcoma incidence [32].

In metastatic forms of osteosarcoma, some specific genetic changes have been observed which include upregulation of Wnt/ $\beta$-catenin and src pathway, Notch1 and Notch2 receptors. Besides, downregulation of Fas/ Fas ligand pathway (a cell death pathway) [33, 34]. Furthermore, angiogenic enzymes and growth factors (e.g. IL-8, PDGF-R, EGFR, and VEGF) are helpful for tumor progression and growth in target cells. Src pathway which is reactivated results in tumor hyper-proliferation and neovascularity $[35,36]$. The heterogeneity in the genotype of osteosarcoma has translated into several expression profiles of macromolecular biomarkers which are helpful in the clinic. A variety of studies have found abnormally-expressed levels of certain proteins and mRNAs, such as HMGB1, ErbB-2, FBXW7, cathepsin

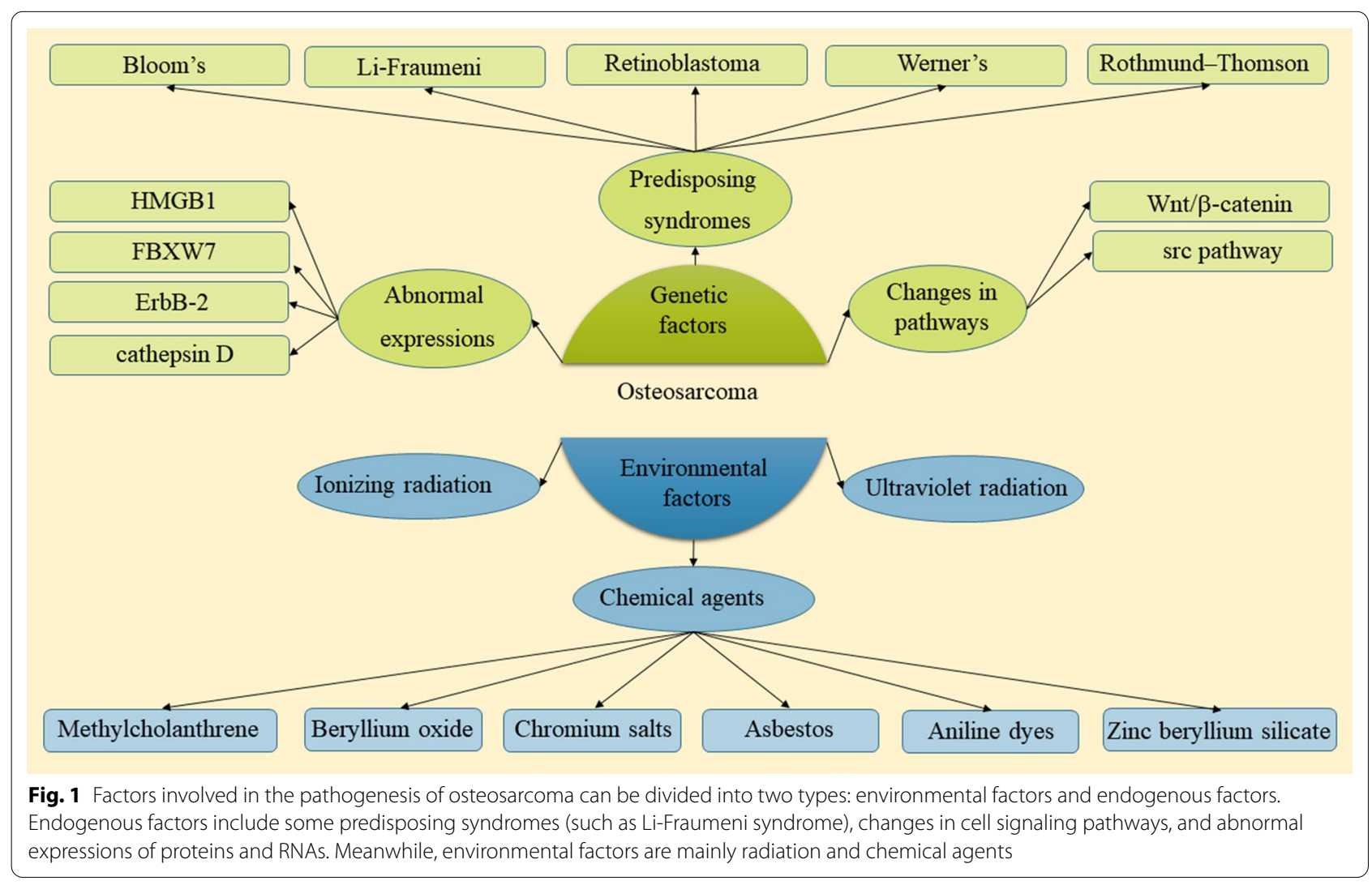


$D$, and miR-421. Nevertheless, the significance of these biomarkers is still under investigation and controversy [37-41].

Among the environmental factors that are suggested as carcinogens of osteosarcoma, ultraviolet and ionizing radiation are well-established [42]. In only $2 \%$ of osteosarcoma cases, radiation exposure is implicated [43]. Moreover, data suggest that radiation does not play a significant role in the pediatric form of the disease. Between the exposure to radiation and the formation of osteosarcoma, there is an interval of 10-20 years [44]. Some chemical agents are also reported to be associated with the formation of osteosarcoma, including asbestos, methylcholanthrene, zinc beryllium silicate, chromium salts, aniline dyes, and beryllium oxide [45-48].

\section{Quercetin is a natural compound with a variety of advantages}

The name of "Flavonoid" reminds us of a group of natural substances which are mostly found in vegetables [49]. These substances which encompass phenolic structures are classified into 6 subclasses: flavones, isoflavones, flavanones, flavonols, flavan-3-ols (flavanols), and anthocyanins [50]. Quercetin is a member of the flavonol group and is derived from quercetum (oak forest) [49, 51]. Apples, berries, onions, tea, tomatoes, and many seeds and nuts have quercetin as one of their ingredients $[51,52]$. This polyphenol is one of the most investigated flavonols due to the diversity of its effects including anti-oxidative, anti-inflammatory, hepatoprotective, genoprotective, cytoprotective, and angioprotective [53, 54]. Investigations regarding the therapeutic applications of quercetin have shown its effectiveness on a number of diseases such as arthritis, allergy, diabetes, viral and bacterial infections, and finally cancer [53]. Before discussing the anti-cancer properties of quercetin, we would explain the mechanisms by which it is adsorbed, transferred, and metabolized inside the body.

The most common form of quercetin in nature is quercetin glycoside which is known to have poor bioavailability in the oral cavity [51]. In other parts of the gastrointestinal tract, quercetin adsorption is dependent on several factors especially the attached functional groups but the small intestine is the major adsorption site for quercetin glycosides [51]. Quercetin glycosides are deglycosylated in this site by the lactase phlorizin hydrolase $(\mathrm{LPH})$ in order to form quercetin aglycone [55]. Afterward, quercetin aglycon enters stage II of the metabolism process $[55,56]$.

Quercetin gets metabolized in the small intestine through the xenobiotic metabolism which is made up of three stages: modification, conjugation, and elimination [57]. The metabolites of stage II, which are the results of glucuronidation, sulfation, and methylation, experience two different events: some of them are secreted into the portal and lymph circulation and some other metabolites go through elimination in the small intestine [53, 57]. In the liver, these metabolites get conjugated again and eventually, either enter the circulation or the bile [55]. Noteworthy, several factors involved in the regulation of these three stages of the quercetin metabolism are landmarks of its bioavailability [53]. The bioavailability of this agent is nearly $16 \%$ when ingested as a suspension and this poor bioavailability is mostly related to its absorption and biliary elimination [58]. However, a $44.8 \%$ bioavailability is also reachable for quercetin when administering quercetin aglycone solubilized in ethanol [59].

After all, despite this feature of quercetin getting in the way of its applications, still, quercetin is considered an advantageous agent for therapeutic purposes. Investigations have approved its efficacy when used in a great number of diseases including cardiovascular diseases, diabetes, neurodegenerative diseases such as Alzheimer's disease, arthritis, asthma, inflammatory bowel disease, and gastric ulcer [54, 60-69]. From a cancer point of view, quercetin affects many cancer hallmarks, such as proliferation, apoptosis, and autophagy, by the means of its properties (Fig. 2) [70-72]. For instance, quercetin is able to protect cells against oxidative stress by decreasing the number of reactive oxygen species (ROS) [70]. Subsequently, signaling pathways induced by ROS which are participating in cancer initiation/progression are inhibited by quercetin $[70,73]$. In this regard, a great body of

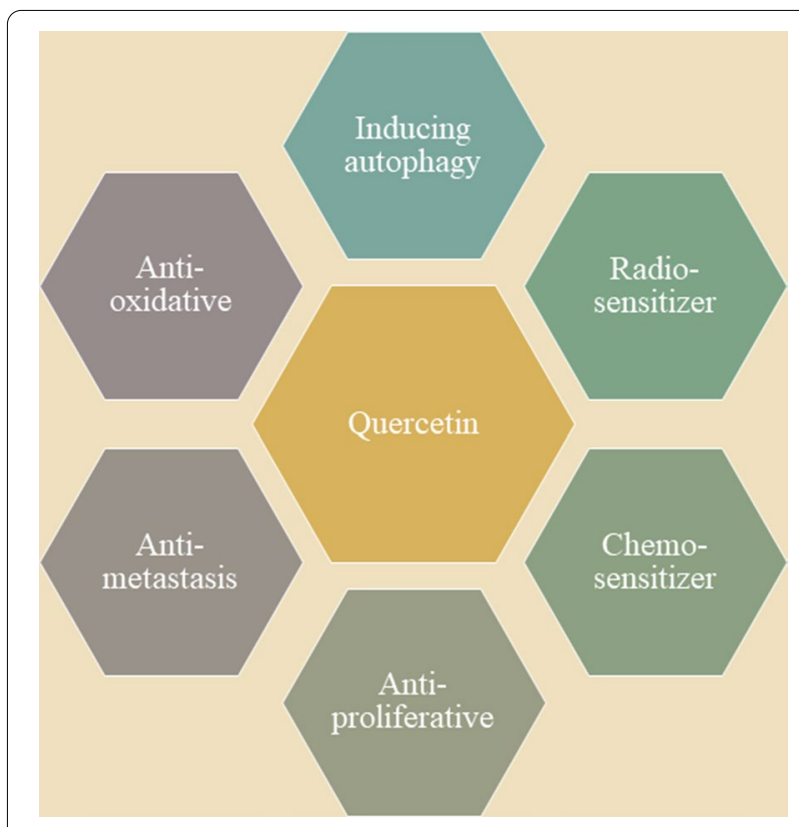

Fig. 2 Quercetin beneficial roles in cancer treatment 
research has examined quercetin on different types of cancer. Anti-apoptotic effects of this favorable agent are observed in breast, colon, prostate, myeloma, pheochromocytoma, acute lymphoblastic leukemia, and ovarian cancer [74]. According to evidence, the vast majority of cancer types are prone to be affected by the anti-proliferative impacts of quercetin [75-77].

Additionally, quercetin also exerts some anti-metastasis effects through affecting inhibition of receptor for advanced glycation end products (RAGE) expression, c-MYC reduction, STAT3 signaling inhibition, inhibiting mesenchymal to epithelial transition (EMT), and increasing the invasiveness of the gastric, lung, bladder, and pancreatic cancerous cells [13, 78-81]. On the other hand, quercetin also has the capacity of targeting cancer cells in another way: chemo-sensitizing [82-85]. This effect of quercetin is mainly investigated in prostate cancer and it seems that it's possible through regulating androgen receptor and PI3K/Akt signaling pathways [84]. Recent researches have demonstrated that radio-sensitizing is also detectable after quercetin treatment in bladder and colon cancer [86, 87]. After all, it seems that quercetin is a proper option for cancer treatment either alone or in combination with other therapeutic agents.

\section{Quercetin and osteosarcoma}

Studies have shown that quercetin plays a variety of antitumor roles against osteosarcoma (Table 1). Although these studies are mainly limited to in vivo and in vitro investigations, findings are promising (Fig. 3). In canine osteosarcoma cell lines, DSN and D-17, quercetin is indicated to reduce proliferation, change cell cycle and ROS levels, and increase apoptosis as well as altering the depolarization of mitochondria and calcium cytoplasmic concentration [88]. Besides, quercetin increases the phosphorylation of c-Jun N-terminal kinase, ERK1/2, P38, and P90RSK proteins. Meanwhile, it inhibits the phosphorylation of S6, AKT, and P70S6K proteins [88]. Evidence demonstrated that heat shock response leads to the reduction of glucocorticoid receptor binding activity in human osteosarcoma cell line HOS-8603 [89]. A study has shown that quercetin is able to suppress the mRNA expressions of heat shock protein (HSP) $90 \alpha$ and HSP 70. However, it cannot abolish the reduction of glucocorticoid receptors during heat shock treatment. Also, it is found that quercetin-induced downregulation of glucocorticoid receptor is accompanied by a reduction in functional responses that are mediated by glucocorticoid [89].

\section{Inhibiting proliferation, migration, and invasion}

A study has also reported that quercetin treatment results in various antitumor effects in human osteosarcoma cell line 143B, including suppression of proliferation, cell cycle arrest at G2/M phase, induction of apoptosis, and reduced potential of cells for adhesion and migration [90]. Lan and colleagues have indicated that quercetin leads to a reduction in invasion and migration of osteosarcoma HOS and MG-63 cells [91]. They reported that quercetin-treated HOS cells show lower mRNA and protein levels of VEGF, HIF-1 $\alpha$, MMP2, and MMP9. Furthermore, the formation and growth of metastatic lung tumors are suppressed by quercetin treatment as studies in the nude mouse osteosarcoma model [91].

Quercetin treatment is shown to significantly reduce the cell viability of osteosarcoma U2OS and Saos-2 cells after $48 \mathrm{~h}$ of incubation [92]. Quercetin also significantly

Table 1 Studies investigated the antitumor roles of quercetin on human osteosarcoma

\begin{tabular}{|c|c|c|c|c|}
\hline Dose(s) & Duration of incubation & Quercetin's effect & Cell line(s) & Ref. \\
\hline 80 and $100 \mu \mathrm{M}$ & $48 \mathrm{~h}$ & Inhibits proliferation and metastasis through suppressing PTHR1 & U2OS and Saos-2 & {$[92]$} \\
\hline 25 or $50 \mu \mathrm{M}$ & $18 \mathrm{~h}$ & Suppresses proliferation and migration while inducing apoptosis & $143 B$ & {$[90]$} \\
\hline 25,50 and $100 \mu \mathrm{M}$ & 12 and $24 \mathrm{~h}$ & Suppresses metastatic lung tumors & HOS and MG-63 & {$[91]$} \\
\hline 10,25 or $50 \mu \mathrm{M}$ & $48 \mathrm{~h}$ & $\begin{array}{l}\text { Induces apoptosis by mitochondrial dysfunction and dephos- } \\
\text { phorylation of Akt }\end{array}$ & U2OS/MTX300 & {$[94]$} \\
\hline- & - & $\begin{array}{l}\text { Reduces mitochondrial membrane potential and release of } \\
\text { mitochondrial cytochrome c to cytosol while dephosphorylat- } \\
\text { ing Akt }\end{array}$ & U2OS/MTX300 & {$[95]$} \\
\hline 50,100 and $200 \mu \mathrm{M}$ & $24 \mathrm{~h}$ & Induces autophagy by the ROS-NUPR1 pathway & MG-63 & {$[97]$} \\
\hline $10,100,200,500$ and $1000 \mu \mathrm{M}$ & $48 \mathrm{~h}$ & Induces apoptosis and cell cycle arrest at G(1)/S & HOS & {$[96]$} \\
\hline $20,40,80,160,240$ and $320 \mu \mathrm{M}$ & $48 \mathrm{~h}$ & $\begin{array}{l}\text { Induces apoptosis via a mitochondrial-dependent pathway and } \\
\text { reduces cell viability }\end{array}$ & MG-63 & {$[93]$} \\
\hline- & - & Downregulated glucocorticoid receptors in osteosarcoma cells & HOS-8603 & {$[89]$} \\
\hline $5 \mu \mathrm{M}$ & $24 \mathrm{~h}$ & Improves cisplatin sensitivity by miR-217/KRAS axis & $143 B$ & {$[98]$} \\
\hline $50 \mu \mathrm{M}$ & $48 \mathrm{~h}$ & $\begin{array}{l}\text { Leads to the alteration in G1/S phase and reduction in cyclin D1 } \\
\text { in U2OSPt }\end{array}$ & U2OS and U2OSPt & {$[99]$} \\
\hline
\end{tabular}




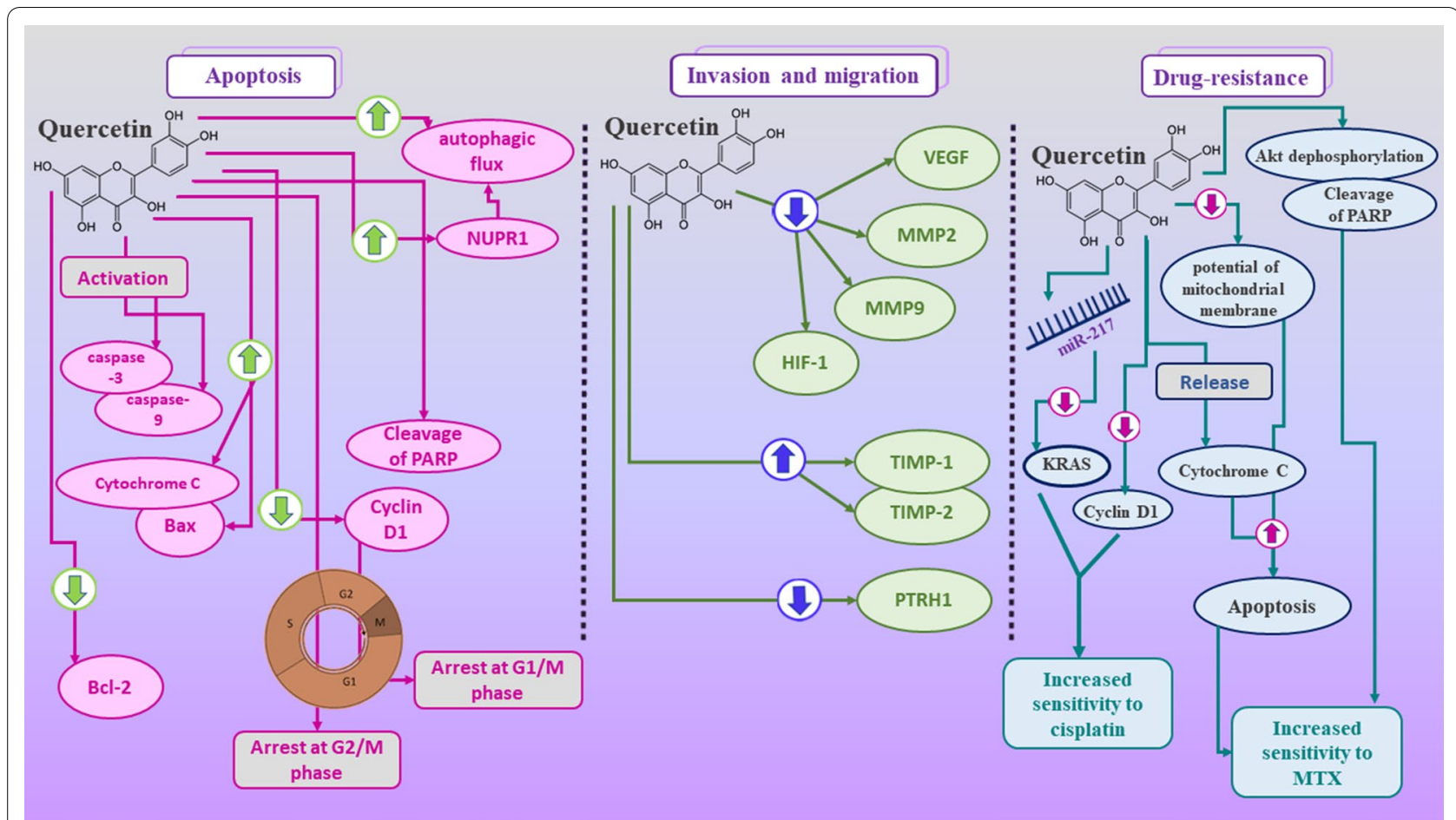

Fig. 3 A summary of quercetin roles in osteosarcoma which include inducing apoptosis and suppressing proliferation as well as inhibiting migration and invasion. Furthermore, quercetin is shown to be effective in overcoming drug-resistance in osteosarcoma cells. To exert its anti-tumor roles, quercetin affects several molecular and cellular signaling pathways, such as VEGF, MMPs, caspases, AKT, and KRAS. Downward arrows represent downregulation or reduction. Upward arrows shows upregulation or increase

reduces the invasion, adhesion, and migration of cancer cells. It is reported that quercetin is able to decrease the expression of matrix metalloproteinases (MMP)-2 and -9 at the mRNA level. Meanwhile, it increases the mRNA expression of tissue inhibitors of metalloproteinases (TIMP)-1 and -2.80 and $100 \mu \mathrm{M}$ of quercetin leads to a significant reduction in parathyroid hormone receptor 1 (PTRH1) mRNA level by respectively, 0.27 - and 0.55 -fold in U2OS cells and 0.19 and 0.41 -folds in Saos-2 cells. Furthermore, quercetin anti-tumor effects on osteosarcoma cell lines are improved by PTHR1 knockdown [92].

\section{Quercetin-induced induction of autophagy and apoptosis}

Liang et al. [93] have found that quercetin inhibits the viability of human osteosarcoma MG-63 cells in a dose-dependent manner. They reported that quercetin treatment results in the activation of caspase- 3 and -9 , downregulation of $\mathrm{Bcl}-2$, upregulation of Bax and cytochrome $\mathrm{C}$, and loss of mitochondrial membrane potential. Based on this evidence, it is suggested that quercetin-induced apoptosis may be mediated by the mitochondrial-dependent pathway [93]. Another study has demonstrated that quercetin suppresses the viability of methotrexate (MTX)-resistant osteosarcoma cell line U2OS/MTX300 cells in a dose-dependent manner [94]. As evidenced by fluorescence staining and flow cytometry, quercetin induces apoptosis in the MTXresistant cells, paralleled by a decrease in the potential of mitochondrial membrane, caspase- 3 activation, mitochondrial cytochrome $\mathrm{c}$ release, Bax upregulation, and downregulation of $\mathrm{p}-\mathrm{Bad}$ and $\mathrm{Bcl}-2$. Followed by quercetin treatment, Akt dephosphorylation is observed. Active Akt plays a protective role against the Akt dephosphorylation, Bad, and degradation of poly(ADP-ribose) polymerase (PARP). Whereas, the combination of quercetin with LY294002 promotes the Bad and Akt dephosphorylation and cleavage of PARP [94]. The same result is concluded in a study by Yin et al. [95]. They reported that quercetin suppresses the proliferation and induces apoptosis in U2OS/MTX300 cells, suggesting that these might be associated with the apoptosis pathway of mitochondria and Akt activity [95]. Studies have also shown that quercetin treatment leads to the cell cycle arrest at G(1)/S phase accompanied by cyclin D1 downregulation [96]. Subsequently, caspase-3 activation and PARP cleavage induce apoptosis [96].

Quercetin's ability to induce cell death in osteosarcoma cell lines is not limited to apoptosis. As shown by Wu and 
colleagues, incubation of MG-63 cells with quercetin for $24 \mathrm{~h}$ leads to an increase in autophagic flux [97]. Downregulation of $\mathrm{P} 62 / \mathrm{SQSTM} 1$ and upregulation of LC3BII/LC3B-I are confirming evidence of this effect. Using Bafilomycin A1, an inhibitor of autophagy, or blocking autophagy by knockdown of ATG5 causes a reduction in cell death induced by quercetin. Results indicate that quercetin treatment results in higher expression of NUPR1 and activation of NUPR1 reporter activity, leading to the expression of genes related to autophagy. Besides, NURP1 is reported to be associated with the dysregulation in the hemostasis of reactive oxygen species (ROS) which can be suppressed by NAC inhibiting intracellular ROS. Furthermore, in vivo studies reveal that quercetin-induced autophagy is suppressed by NAC [97].

\section{The role of quercetin in overcoming drug-resistance in osteosarcoma cell lines}

$5 \mu \mathrm{M}$ quercetin is shown to increase the sensitivity of $143 \mathrm{~B}$ cells to cisplatin treatment. Cisplatin and/or quercetin treatment leads to the upregulation of miR-217 and downregulation of KRAS, the target of miR-217, at both protein and mRNA levels. Knockdown of miR-217 abolishes the improved sensitivity to cisplatin. Meanwhile, overexpression of miR-217 leads to the opposite results, demonstrating that the miR-217-KRAS axis is involved in the quercetin-improved sensitivity of cisplatin [98]. Following the treatment with $50 \mu \mathrm{M}$ quercetin for $48 \mathrm{~h}$, the expression level of cyclin D1 is shown to be reduced in the cisplatin-resistance osteosarcoma cell line, U2OSPt; however, this did not occur in U2OS cells [99]. Moreover, it is reported that cyclin D1 decrease can be related to the changes in the G1/S phase following the quercetin treatment [99]. Altogether, these findings suggest that quercetin can be used alone as an anti-tumor agent or in combination with other cytotoxic agents as a synergistic compound.

\section{Conclusions}

Osteosarcoma is a primary bone malignancy in both children and adults which is not considered to be common cancer. The number of newly diagnosed patients is not high but this fact has not affected its survival rate which recently has been enhanced to $60 \%$. Other than the low efficacy of the common treatments, side effects of these methods are also interfering with the life quality of osteosarcoma patients especially the ones developing osteosarcoma at a young age. Considering this, increasing the effectiveness of common methods and decreasing their side effects would be a great help for osteosarcoma patients. Quercetin is a plant compound that has shown to be suitable for cancer treatment in recent years. Therefore, we tried to gather evidence on how quercetin is able to inhibit osteosarcoma in order to suggest a new candidate for the treatment of this cancer. In the osteosarcoma viewpoint, abundant effects of this agent have been indicated to be useful for inducing apoptosis, cell cycle arrest, and autophagy and reducing proliferation, viability, invasion, chemo-resistance, and migration (Figs. 1, 2 and 3). Nevertheless, for a complete confirmation of these effects and a wider usage in clinics, human studies in this field are required. As mentioned before, quercetin has a low bioavailability in the human body which increases the need for examining this agent on humans who are developing osteosarcoma. Moreover, the side effects of quercetin as an antitumor agent have not been fully investigated in previous studies and need to be addressed. Taken together, in this paper we have shown that quercetin executes a wide range of mechanisms for preventing osteosarcoma from progression; thus, it has the potential to become a common method in osteosarcoma management.

\section{Abbreviations}

MMP: Matrix metalloproteinases; TIMP: Tissue inhibitors of metalloproteinases; MTX: Methotrexate; PARP: Poly(ADP-ribose) polymerase; ROS: Reactive oxygen species; HSP: Heat shock protein; LPH: Lactasephlorizin hydrolase; RAGE: Receptorfor advanced glycation end products; EMT: Mesenchymalto epithelial transition; PTRH1: Parathyroid hormone receptor 1.

\section{Acknowledgements}

Not applicable.

\section{Authors' contributions}

FS, PM-D, ZA and BY contributed in conception, design and drafting of the manuscript. All authors read and approved the final manuscript.

Funding

Not applicable.

Availability of data and materials

Not applicable.

\section{Declarations}

Ethics approval and consent to participate Not applicable.

\section{Consent for publication}

Not applicable.

\section{Competing interests}

The authors declare no conflict of interest.

\section{Author details}

${ }^{1}$ Research Center for Biochemistry and Nutrition in Metabolic Diseases, Institute for Basic Sciences, Kashan University of Medical Sciences, Kashan, I.R. of Iran. ${ }^{2}$ Stem Cell Research Center, Tabriz University of Medical Sciences, Tabriz, Iran. ${ }^{3}$ Department of Biochemistry, Faculty of Medicine, Tabriz University of Medical Sciences, Tabriz, Iran. 
Received: 29 April 2021 Accepted: 29 June 2021

Published online: 05 July 2021

\section{References}

1. Durfee RA, Mohammed M, Luu HH. Review of osteosarcoma and current management. Rheumatol Ther. 2016;3:221-43.

2. Hayden JB, Hoang BH. Osteosarcoma: basic science and clinical implications. Orthop Clin N Am. 2006;37:1-7.

3. Whelan JS, Davis LE. Osteosarcoma, chondrosarcoma, and chordoma. J Clin Oncol. 2018;36:188-93.

4. Kager L, Zoubek A, Dominkus M, Lang S, Bodmer N, Jundt G, et al. Osteosarcoma in very young children: experience of the Cooperative Osteosarcoma Study Group. Cancer. 2010;116:5316-24.

5. Casali PG, Bielack S, Abecassis N, Aro HT, Bauer S, Biagini R, et al. Bone sarcomas: ESMO-PaedCan-EURACAN clinical practice guidelines for diagnosis, treatment and follow-up. Ann Oncol. 2018;29:iv79-95.

6. Czarnecka AM, Synoradzki K, Firlej W, Bartnik E, Sobczuk P, Fiedorowicz M, et al. Molecular biology of osteosarcoma. Cancers. 2020;12:2130.

7. Anand David AV, Arulmoli R, Parasuraman S. Overviews of biological importance of quercetin: a bioactive flavonoid. Pharmacogn Rev. 2016;10:84-9.

8. Thomasset SC, Berry DP, Garcea G, Marczylo T, Steward WP, Gescher AJ. Dietary polyphenolic phytochemicals-promising cancer chemopreventive agents in humans? A review of their clinical properties. Int J Cancer. 2007;120:451-8

9. Harwood M, Danielewska-Nikiel B, Borzelleca JF, Flamm GW, Williams GM, Lines TC. A critical review of the data related to the safety of quercetin and lack of evidence of in vivo toxicity, including lack of genotoxic/carcinogenic properties. Food Chem Toxicol. 2007:45:2179-205.

10. Hirpara KV, Aggarwal P, Mukherjee AJ, Joshi N, Burman AC. Quercetin and its derivatives: synthesis, pharmacological uses with special emphasis on anti-tumor properties and prodrug with enhanced bio-availability. Anticancer Agents Med Chem. 2009:9:138-61.

11. Wang S, Yao J, Zhou B, Yang J, Chaudry MT, Wang M, et al. Bacteriostatic effect of quercetin as an antibiotic alternative in vivo and its antibacterial mechanism in vitro. J Food Prot. 2018;81:68-78.

12. Eid HM, Haddad PS. The antidiabetic potential of quercetin: underlying mechanisms. Curr Med Chem. 2017;24:355-64.

13. Lei CS, Hou YC, Pai MH, Lin MT, Yeh SL. Effects of quercetin combined with anticancer drugs on metastasis-associated factors of gastric cancer cells: in vitro and in vivo studies. J Nutr Biochem. 2018;51:105-13.

14. Maurya AK, Vinayak M. Quercetin regresses Dalton's lymphoma growth via suppression of PI3K/AKT signaling leading to upregulation of p53 and decrease in energy metabolism. Nutr Cancer. 2015;67:354-63.

15. Darband SG, Kaviani M, Yousefi B, Sadighparvar S, Pakdel FG, Attari JA, et al. Quercetin: a functional dietary flavonoid with potential chemo-preventive properties in colorectal cancer. J Cell Physiol. 2018;233:6544-60.

16. Vafadar A, Shabaninejad Z, Movahedpour A, Fallahi F, Taghavipour M, Ghasemi Y, et al. Quercetin and cancer: new insights into its therapeutic effects on ovarian cancer cells. Cell Biosci. 2020;10:32.

17. Kasiri N, Rahmati M, Ahmadi L, Eskandari N, Motedayyen H. Therapeutic potential of quercetin on human breast cancer in different dimensions. Inflammopharmacology. 2020;28:39-62.

18. Martin JW, Squire JA, Zielenska M. The genetics of osteosarcoma. Sarcoma. 2012:2012:627254

19. Bloom D. Congenital telangiectatic erythema resembling lupus erythematosus in dwarfs; probably a syndrome entity. AMA Am J Dis Child. 1954:88:754-8.

20. Porter DE, Holden ST, Steel CM, Cohen BB, Wallace MR, Reid R. A significant proportion of patients with osteosarcoma may belong to LiFraumeni cancer families. J Bone Joint Surg Br Vol. 1992;74:883-6.

21. Hicks MJ, Roth JR, Kozinetz CA, Wang LL. Clinicopathologic features of osteosarcoma in patients with Rothmund-Thomson syndrome. J Clin Oncol. 2007:25:370-5.

22. Wang LL, Gannavarapu A, Kozinetz CA, Levy ML, Lewis RA, Chintagumpala MM, et al. Association between osteosarcoma and deleterious mutations in the RECQL4 gene in Rothmund-Thomson syndrome. J Natl Cancer Inst. 2003:95:669-74.
23. Draper GJ, Sanders BM, Kingston JE. Second primary neoplasms in patients with retinoblastoma. Br J Cancer. 1986;53:661-71.

24. Matsunaga E. Hereditary retinoblastoma: host resistance and second primary tumors. J Natl Cancer Inst. 1980;65:47-51.

25. Hameed M, Mandelker D. Tumor syndromes predisposing to osteosarcoma. Adv Anat Pathol. 2018;25:217-22.

26. Beckerman R, Prives C. Transcriptional regulation by p53. Cold Spring Harb Perspect Biol. 2010;2:a000935.

27. Miller RW. Contrasting epidemiology of childhood osteosarcoma, Ewing's tumor, and rhabdomyosarcoma. National Cancer Institute monograph. 1981. p. 9-15.

28. Lonardo F, Ueda T, Huvos AG, Healey J, Ladanyi M. p53 and MDM2 alterations in osteosarcomas: correlation with clinicopathologic features and proliferative rate. Cancer. 1997:79:1541-7.

29. Goodrich DW, Wang NP, Qian YW, Lee EY, Lee WH. The retinoblastoma gene product regulates progression through the $\mathrm{G} 1$ phase of the cell cycle. Cell. 1991;67:293-302.

30. Wadayama B, Toguchida J, Shimizu T, Ishizaki K, Sasaki MS, Kotoura Y, et al. Mutation spectrum of the retinoblastoma gene in osteosarcomas. Cancer Res. 1994:54:3042-8.

31. Feugeas O, Guriec N, Babin-Boilletot A, Marcellin L, Simon P, Babin S, et al. Loss of heterozygosity of the RB gene is a poor prognostic factor in patients with osteosarcoma. J Clin Oncol. 1996;14:467-72.

32. Mohaghegh P, Hickson ID. DNA helicase deficiencies associated with cancer predisposition and premature ageing disorders. Hum Mol Genet. 2001;10:741-6

33. Lafleur EA, Koshkina NV, Stewart J, Jia SF, Worth LL, Duan X, et al. Increased Fas expression reduces the metastatic potential of human osteosarcoma cells. Clin Cancer Res. 2004;10:8114-9.

34. Worth LL, Lafleur EA, Jia SF, Kleinerman ES. Fas expression inversely correlates with metastatic potential in osteosarcoma cells. Oncol Rep. 2002;9:823-7.

35. Kim LC, Song L, Haura EB. Src kinases as therapeutic targets for cancer. Nat Rev Clin Oncol. 2009:6:587-95.

36. Hingorani P, Zhang W, Gorlick R, Kolb EA. Inhibition of Src phosphorylation alters metastatic potential of osteosarcoma in vitro but not in vivo. Clin Cancer Res. 2009;15:3416-22.

37. He J, Zhang P, Li Q, Zhou D, Liu P. Expression of high mobility group box 1 protein predicts a poorer prognosis for patients with osteosarcoma. Oncol Lett. 2016:11:293-8.

38. Li Z, Xiao J, Hu K, Wang G, Li M, Zhang J, et al. FBXW7 acts as an independent prognostic marker and inhibits tumor growth in human osteosarcoma. Int J Mol Sci. 2015;16:2294-306.

39. Gemoll T, Epping F, Heinrich L, Fritzsche B, Roblick UJ, Szymczak S, et al. Increased cathepsin D protein expression is a biomarker for osteosarcomas, pulmonary metastases and other bone malignancies. Oncotarget. 2015:6:16517-26

40. Akatsuka T, Wada T, Kokai Y, Kawaguchi S, Isu K, Yamashiro K, et al. ErbB2 expression is correlated with increased survival of patients with osteosarcoma. Cancer. 2002;94:1397-404.

41. Onda M, Matsuda S, Higaki S, lijima T, Fukushima J, Yokokura A, et al. ErbB-2 expression is correlated with poor prognosis for patients with osteosarcoma. Cancer. 1996:77:71-8.

42. Polednak AP. Bone cancer among female radium dial workers. Latency periods and incidence rates by time after exposure: brief communication. J Natl Cancer Inst. 1978;60:77-82.

43. Picci P. Osteosarcoma (osteogenic sarcoma). Orphanet J Rare Dis. 2007:2:1-4.

44. Longhi A, Barbieri E, Fabbri N, Macchiagodena M, Favale L, Lippo C, et al. Radiation-induced osteosarcoma arising 20 years after the treatment of Ewing's sarcoma. Tumori. 2003;89:569-72.

45. Rani AS, Kumar S. Transformation of non-tumorigenic osteoblast-like human osteosarcoma cells by hexavalent chromates: alteration of morphology, induction of anchorage-independence and proteolytic function. Carcinogenesis. 1992;13:2021-7.

46. Dutra FR, Largent EJ. Osteosarcoma induced by beryllium oxide. Am J Pathol. 1950;26:197-209.

47. Mazabraud A. Experimental production of bone sarcomas in the rabbit by a single local injection of beryllium. Bull Cancer. 1975;62:49-58.

48. Tan ML, Choong PF, Dass CR, Osteosarcoma. Conventional treatment vs. gene therapy. Cancer Biol Ther. 2009;8:106-17. 
49. Panche AN, Diwan AD, Chandra SR. Flavonoids: an overview. J Nutr Sci. 2016;5:e47.

50. Yamagata K. Metabolic syndrome: preventive effects of dietary flavonoids. Stud Nat Prod Chem. 2019;60:1-28.

51. LiY, Yao J, Han C, Yang J, Chaudhry MT, Wang S, et al. Quercetin, inflammation and Immunity. Nutrients. 2016;8:167.

52. Zhang Y, Li Y, Cao C, Cao J, Chen W, Zhang Y, et al. Dietary flavonol and flavone intakes and their major food sources in Chinese adults. Nutr Cancer. 2010:62:1120-7.

53. D'Andrea G, Quercetin. A flavonol with multifaceted therapeutic applications? Fitoterapia. 2015;106:256-71.

54. Saccol R, da Silveira KL, Manzoni AG, Abdalla FH, de Oliveira JS, Dornelles $\mathrm{GL}$, et al. Antioxidant, hepatoprotective, genoprotective, and cytoprotective effects of quercetin in a murine model of arthritis. J Cell Biochem. 2020;121:2792-801.

55. Arts IC, Sesink AL, Faassen-Peters M, Hollman PC. The type of sugar moiety is a major determinant of the small intestinal uptake and subsequent biliary excretion of dietary quercetin glycosides. Br J Nutr. 2004;91:841-7.

56. Németh K, Plumb GW, Berrin J-G, Juge N, Jacob R, Naim HY, et al. Deglycosylation by small intestinal epithelial cell $\beta$-glucosidases is a critical step in the absorption and metabolism of dietary flavonoid glycosides in humans. Eur J Nutr. 2003:42:29-42.

57. Guo Y, Bruno RS. Endogenous and exogenous mediators of quercetin bioavailability. J Nutr Biochem. 2015;26:201-10.

58. Khaled KA, El-Sayed YM, Al-Hadiya BM. Disposition of the flavonoid quercetin in rats after single intravenous and oral doses. Drug Dev Ind Pharm. 2003;29:397-403.

59. Walle T, Walle UK, Halushka PV. Carbon dioxide is the major metabolite of quercetin in humans. J Nutr. 2001;131:2648-52.

60. Costa LG, Garrick JM, Roquè PJ, Pellacani C. Mechanisms of neuroprotection by quercetin: counteracting oxidative stress and more. Oxid Med Cell Longev. 2016;2016:2986796.

61. Dabeek WM, Marra MV. Dietary Quercetin and kaempferol: bioavailability and potential cardiovascular-related bioactivity in humans. Nutrients. 2019:11:2288.

62. Habtemariam S, Belai A. Natural therapies of the inflammatory bowel disease: the case of rutin and its aglycone, quercetin. Mini Rev Med Chem. 2018;18:234-43.

63. Khan $\mathrm{H}$, Ullah H, Aschner M, Cheang WS, Akkol EK. Neuroprotective effects of quercetin in Alzheimer's disease. Biomolecules. 2019;10:59.

64. Piovezana Bossolani GD, Silva BT, Colombo Martins Perles JV, Lima MM, Vieira Frez FC, de GarciaSouza SR, et al. Rheumatoid arthritis induces enteric neurodegeneration and jejunal inflammation, and quercetin promotes neuroprotective and anti-inflammatory actions. Life Sci. 2019;238:116956.

65. Cesarone MR, Belcaro G, Hu S, Dugall M, Hosoi M, Ledda A, et al. Supplementary prevention and management of asthma with quercetin phytosome: a pilot registry. Minerva Med. 2019;110:524-9.

66. Abdel-Tawab MS, Mostafa Tork O, Mostafa-Hedeab G, Ewaiss Hassan $M$, Azmy Elberry D. Protective effects of quercetin and melatonin on indomethacin induced gastric ulcers in rats. Rep Biochem Mol Biol. 2020;9:278-90.

67. Alkushi AGR, Elsawy NAM. Quercetin attenuates, indomethacin-induced acute gastric ulcer in rats. Folia Morphol. 2017;76:252-61.

68. Chen $\mathrm{S}$, Jiang $\mathrm{H}, \mathrm{Wu} \mathrm{X}$, Fang J. Therapeutic effects of quercetin on inflammation, obesity, and type 2 diabetes. Mediat Inflamm. 2016;2016:9340637.

69. Ebrahimpour S, Zakeri M, Esmaeili A. Crosstalk between obesity, diabetes, and alzheimer's disease:introducing quercetin as an effective triple herbal medicine. Ageing Res Rev. 2020;62:101095.

70. Reyes-Farias M, Carrasco-Pozo C. The anti-cancer effect of quercetin: molecular implications in cancer metabolism. Int J Mol Sci. 2019;20:3177.

71. Sezer ED, Oktay LM, Karadadaş E, Memmedov H, Selvi Gunel N, Sözmen E. Assessing anticancer potential of blueberry flavonoids, quercetin, kaempferol, and gentisic acid, through oxidative stress and apoptosis parameters on HCT-116 cells. J Med Food. 2019;22:1118-26.

72. Tang SM, Deng XT, Zhou J, Li QP, Ge XX, Miao L. Pharmacological basis and new insights of quercetin action in respect to its anti-cancer effects. Biomed Pharmacother $=$ Biomedecine \& Pharmacotherapie. 2020;121:109604.
73. Cebecioglu R, Yildirim M, Akagunduz D, Korkmaz I, Tekin HO, AtaseverArslan B, et al. Synergistic effects of quercetin and selenium on oxidative stress in endometrial adenocarcinoma cells. Bratislavske lekarske listy. 2019;120:449-55.

74. Hashemzaei M, Delarami Far A, Yari A, Heravi RE, Tabrizian K, Taghdisi SM, et al. Anticancer and apoptosis-inducing effects of quercetin in vitro and in vivo. Oncol Rep. 2017;38:819-28.

75. Dong Y, Yang J, Yang L, Li P. Quercetin inhibits the proliferation and metastasis of human non-small cell lung cancer cell line: the key role of Src-mediated fibroblast growth factor-inducible 14 (Fn14)/nuclear factor kappa B (NF-KB) pathway. Med Sci Monit. 2020;26:e920537.

76. Ren KW, Li YH, Wu G, Ren JZ, Lu HB, Li ZM, et al. Quercetin nanoparticles display antitumor activity via proliferation inhibition and apoptosis induction in liver cancer cells. Int J Oncol. 2017:50:1299-311.

77. Srivastava NS, Srivastava RAK. Curcumin and quercetin synergistically inhibit cancer cell proliferation in multiple cancer cells and modulate Wnt/ $\beta$-catenin signaling and apoptotic pathways in A375 cells. Phytomedicine. 2019;52:117-28.

78. Chen KC, Hsu WH, Ho JY, Lin CW, Chu CY, Kandaswami CC, et al. Flavonoids luteolin and quercetin inhibit RPS19 and contributes to metastasis of cancer cells through c-Myc reduction. J Food Drug Anal. 2018:26:1180-91.

79. Lee YH, Tuyet PT. Synthesis and biological evaluation of quercetin-zinc (II) complex for anti-cancer and anti-metastasis of human bladder cancer cells. In Vitro Cell Dev Biol Anim. 2019;55:395-404.

80. Yu D, Ye T, Xiang Y, Shi Z, Zhang J, Lou B, et al. Quercetin inhibits epithelial-mesenchymal transition, decreases invasiveness and metastasis, and reverses IL-6 induced epithelial-mesenchymal transition, expression of MMP by inhibiting STAT3 signaling in pancreatic cancer cells. OncoTargets Ther. 2017;10:4719-29.

81. Zhao $X$, Zhang J. Mechanisms for quercetin in prevention of lung cancer cell growth and metastasis. Zhong nan da xue xue bao Yi xue ban $=1$ Cent South Univ Med Sci. 2015:40:592-7.

82. Hussain Y, Mirzaei S, Ashrafizadeh M, Zarrabi A, Hushmandi K, Khan H, et al. Quercetin and its nano-scale delivery systems in prostate cancer therapy: paving the way for cancer elimination and reversing chemoresistance. Cancers. 2021;13:1602.

83. Jaganathan SK. Can flavonoids from honey alter multidrug resistance? Med Hypotheses. 2011;76:535-7.

84. Lu X, Yang F, Chen D, Zhao Q, Chen D, Ping H, et al. Quercetin reverses docetaxel resistance in prostate cancer via androgen receptor and $\mathrm{PI} / 3 \mathrm{~K}$ Akt signaling pathways. Int J Biol Sci. 2020;16:1121-34.

85. Lan CY, Chen SY, Kuo CW, Lu CC, Yen GC. Quercetin facilitates cell death and chemosensitivity through RAGE/PI3K/AKT/mTOR axis in human pancreatic cancer cells. J Food Drug Anal. 2019;27:887-96.

86. Alban L, Monteiro WF, Diz FM, Miranda GM, Scheid CM, Zotti ER, et al. New quercetin-coated titanate nanotubes and their radiosensitization effect on human bladder cancer. Mater Sci Eng C Mater Biol Appl. 2020;110:110662

87. LiY, Wang Z, Jin J, Zhu SX, He GQ, Li SH, et al. Quercetin pretreatment enhances the radiosensitivity of colon cancer cells by targeting Notch-1 pathway. Biochem Biophys Res Commun. 2020;523:947-53.

88. Ryu S, Park S, Lim W, Song G. Quercetin augments apoptosis of canine osteosarcoma cells by disrupting mitochondria membrane potential and regulating PKB and MAPK signal transduction. J Cell Biochem. 2019;120:17449-58.

89. Song L. Relationship between the induction of heat shock proteins and the decrease in glucocorticoid receptor during heat shock response in human osteosarcoma cells. Sci China B Chem Life Sci Earth Sci. 1995:38:1473-81.

90. Berndt K, Campanile C, Muff R, Strehler E, Born W, Fuchs B. Evaluation of quercetin as a potential drug in osteosarcoma treatment. Anticancer Res. 2013;33:1297-306.

91. Lan H, Hong W, Fan P, Qian D, Zhu J, Bai B. Quercetin inhibits cell migration and invasion in human osteosarcoma cells. Cell Physiol Biochem. 2017:43:553-67.

92. Li S, Pei Y, Wang W, Liu F, Zheng K, Zhang X. Quercetin suppresses the proliferation and metastasis of metastatic osteosarcoma cells by inhibiting parathyroid hormone receptor 1. Biomed Pharmacother $=$ Biomedecine \& Pharmacotherapie. 2019;114:108839. 
93. Liang W, Li X, Li C, Liao L, Gao B, Gan H, et al. Quercetin-mediated apoptosis via activation of the mitochondrial-dependent pathway in MG-63 osteosarcoma cells. Mol Med Rep. 2011;4:1017-23.

94. Xie X, Yin J, Jia Q, Wang J, Zou C, Brewer KJ, et al. Quercetin induces apoptosis in the methotrexate-resistant osteosarcoma cell line U2-OS/MTX300 via mitochondrial dysfunction and dephosphorylation of Akt. Oncol Rep. 2011;26:687-93

95. Yin J, Xie X, Jia Q, Wang J, Huang G, Zou C, et al. Effect and mechanism of quercetin on proliferation and apoptosis of human osteosarcoma cell U-2OS/MTX300. Zhongguo Zhong yao za zhi = Zhongguo zhongyao zazhi $=$ China J Chin Mater Med. 2012;37:611-4.

96. Suh DK, Lee EJ, Kim HC, Kim JH. Induction of G(1)/S phase arrest and apoptosis by quercetin in human osteosarcoma cells. Arch Pharm Res. 2010;33:781-5.

97. Wu B, Zeng W, Ouyang W, Xu Q, Chen J, Wang B, et al. Quercetin induced NUPR1-dependent autophagic cell death by disturbing reactive oxygen species homeostasis in osteosarcoma cells. J Clin Biochem Nutr. 2020;67:137-45.

98. Zhang X, Guo Q, Chen J, Chen Z. Quercetin enhances cisplatin sensitivity of human osteosarcoma cells by modulating microRNA-217-KRAS axis. Mol Cells. 2015;38:638-42.

99. Catanzaro D, Ragazzi E, Vianello C, Caparrotta L, Montopoli M. Effect of quercetin on cell cycle and cyclin expression in ovarian carcinoma and osteosarcoma cell lines. Nat Prod Commun. 2015;10:1365-8.

\section{Publisher's Note}

Springer Nature remains neutral with regard to jurisdictional claims in published maps and institutional affiliations.
Ready to submit your research? Choose BMC and benefit from:

- fast, convenient online submission

- thorough peer review by experienced researchers in your field

- rapid publication on acceptance

- support for research data, including large and complex data types

- gold Open Access which fosters wider collaboration and increased citations

- maximum visibility for your research: over $100 \mathrm{M}$ website views per year

At $\mathrm{BMC}$, research is always in progress.

Learn more biomedcentral.com/submissions 